SZLÁVI, Anna

\title{
METAPHORS MATTER \\ The Analysis of Prezi in Search of Visual-Verbal Metaphors
}

For us, academics, whether we are young scholars or experienced professors, giving a presentation is a never-ending challenge. We often feel intimidated not only when facing our audience but also when preparing our visual support. As a frequent conferenceparticipant, I became fascinated by the diversity of presentation visuals, both in style and quality. This fascination later led me to the idea of investigating presentation tools, mainly to see how the characteristics of a software helps or hinders the presentation-making process. In my search I discovered an online presentation tool whose popularity has shown an impressive growth over the past years. It is not just its soaring global expansion that makes Prezi an exciting topic for analysis. The fact that two of its founders are from the same university as the editorial board of this journal makes the present examination a perfect fit for the first international issue.

\section{Prezi Matters}

What is Prezi then and why does it matter? Prezi ${ }^{1}$, at www.prezi.com, is a cloud-based presentation software, known mainly for its zooming feature. It offers much more, though. It offers immense spatial freedom for structuring and communicating our ideas. On an infinite canvas, we are invited to place and manipulate text, image, and audio-video materials wherever and however we feel like. We can group them into units based on what we consider to belong together. Then, by creating paths between these units, we create navigational sequences, thus putting our dynamic presentation into a linear-like display order.

What really makes a difference, compared to the well-known rival, PowerPoint, is Prezi's zooming user interface. As if having a camera, we can pan through our surface freely, zooming in or out, depending on whether we want to see the details or the whole picture. This feature is amazingly helpful both when trying to structure our thoughts into a presentation, that is, in the process of making the presentation, and when trying to explain our thoughts to the audience, that is, in the process of understanding. It is so because Prezi blends two important characteristics of how we learn and process information: we remember landmarks, and we combine landmarks with direction or action. ${ }^{2}$

\footnotetext{
${ }^{1}$ When referring to the software or the company, Prezi is capitalized; otherwise, when referring to individual presentations made with this software, prezi is used.

2 J. Koetsier, "Prezi Hits 30M Users, Doubling Annually, and Has 'Not Used a Dime' of Investors' Money". Venturebeat.com. Posted Nov. 14, 2013, retrieved 10 Jan. 2015: http://venturebeat.com/2013/11/14/prezihits-30m-users-doubling-annually-and-has-not-used-a-dime-of-investors-money.
} 
Not only can we zoom and pan in Prezi, we are also free to rotate and size both our elements and our units as we see fit. Thus, Prezi's Flash- (and recently JavaScript-)based software ${ }^{3}$ offers a huge amount of creative freedom to its users.

And users seem to appreciate it. The company, which was launched in 2009 by cofounders Szabolcs Somlai-Fischer, Péter Halácsy, and Péter Árvai, with the support of Kitchen Budapest and Magyar Telekom, has been presenting incredible growth. First with headquarters in Budapest, Hungary, given that the co-founders, an architect, a computer scientist, and an entrepreneur, are Hungarian, Prezi opened its second office in San Francisco, California, in the same year. After gaining the sponsorship of TED, a series of conferences focusing on the themes of Technology-Education-Design and on the notion of Ideas (are) Worth Spreading (which is why all talks are accessible online for free), Prezi started its global expansion (www.ted.com).

Since 2009 Prezi has opened several offices all around the world and has become available in multiple languages, like Hungarian, Spanish, Portuguese, German, French, Korean, and Japanese, next to English. The most impressive data, however, is the number of signups Prezi is producing from year to year. In October 2013, a headline reported: "Prezi's current 30 million users is a 50 percent increase in just six months, and 1.5 million new users are currently joining the company every month" (Koetsier). In April 2014, the company reached a new landmark with its 40 million users, which translates into 55,000 new signups each and every day. ${ }^{4}$

What is the secret behind this soaring popularity? According to Prezi's motto, "ideas matter". What is then the idea that brought and is still bringing Prezi success?

\section{Theories Matter}

As an active user of Prezi and a researcher of cognitive science, I have developed a hypothesis in search of an explanation for Prezi's skyrocketing statistics. My hypothesis can be divided into two sub-theories.

Hypothesis 1: Prezi offers a metaphorical tool.

As a researcher of metaphors, I always had the feeling, whenever using Prezi, that it is full of them. Metaphor is a basic conceptual process present in language, image, and culture; ${ }^{5}$ in other words, we communicate and think in metaphors. From this comes the second part of my hypothesis.

Hypothesis 2: Prezi's metaphorical tools play a significant role in its popularity.

\footnotetext{
${ }^{3}$ P. Halácsy, "How and Why Prezi Turned to JavaScript - And Why It Took Four Years". Prezi Engineering. Posted July 1, 2014, retrieved 10 Jan 2015: https://medium.com/prezi-engineering/how-and-why-prezi-turned-tojavascript-56e0ca57d135.

${ }^{4}$ M. Butcher, "Prezi Puts On 10M Users Inside 5 Months, Hits 40M". Techcrunch.com. Posted Apr. 9, 2014, retrieved 10 Jan. 2015: http://techcrunch.com/2014/04/09/prezi-puts-on-10m-users-inside-5-months-hits$40 \mathrm{~m}$.

${ }^{5}$ G. Lakoff and M. Johnson, Philosophy in the Flesh: The Embodied Mind and Its Challenge to Western Thought, New York: Basic Books, 1999; Z. Kövecses, Metaphor: A Practical Introduction, New York: Oxford University Press, 2002; C. Forceville, "Non-Verbal and Multimodal Metaphor in a Cognitivist Framework: Agendas for Research", in G. Kristiansen, M. Achard, R. Dirven and F. J. Ruiz de Mendoza Ibáňez (eds.), Cognitive Linguistics: Current Applications and Future Perspectives, Berlin: Mouton de Gruyter, 2006; Z. Kövecses and R. Benczes, Kognitív nyelvészet [Cognitive Linguistics], Budapest: Akadémiai Kiadó, 2010.
} 
If Prezi proves to model the way we think, it seems logical to presume that its popularity comes largely from its conceptual ergonomics: its use of the fundamental conceptual process, metaphor.

To test my hypotheses, I worked out a three-level examination process. Firstly, I set myself to scrutinize Prezi's website, searching how the company defines its service. Secondly, I turned to the analysis of the user interface, checking the details of what users are offered when making a prezi. Thirdly, I contacted the company for insider statistical data for research purposes. Following my request, I was given stats and samples, which formed the next level of my examination.

My goal was to explore the presence and use of metaphors, on the one hand. The essence of metaphor is that it helps to understand an abstract concept, like that of life, by connecting it with a more concrete, thus, more easily apprehensible, experience, for example, of a journey. People tend to perceive similarities in the features of life and journeys (they both have difficulties/obstacles, choices/crossroads, goals/destinations, etc.), which provides basis for their metaphoric connection. ${ }^{6}$ Sentences like She has gone through a lot in life or We are at crossroads embody this metaphoric relation. According to my theory, metaphors, such as the above LIFE IS A JOURNEY, ${ }^{7}$ will appear in the visual messages of prezis, just like they appear in our natural verbal expressions.

Next to metaphor, I was also interested in the characteristics of frames in Prezi. The idea behind a frame is that every meaning is relative and can only be understood within a certain context, which entails a whole range of related knowledge. ${ }^{8}$ The BALL, interpreted within the FOOTBALL frame, the MAGICIAN frame, or the BABY frame, activates a fundamentally different reading and associates fundamentally different emotions. I figured, the interpretation of presentational content will depend a lot on the frame chosen for the presentation. Similarly, the frame will also determine what kind of content can be used with it.

\section{Philosophy Matters}

First of all, the research called for a scrutiny of Prezi's website. I was looking for how the company defines its product and if any metaphorical reference surfaces in its philosophy. It turned out, Prezi's manifesto abounds in what I was seeking for.

"Prezi is a virtual whiteboard."

The company starts its self-definition with an obvious metaphor. Comparing the relevance of the software in our virtual world to the appearance of the blackboard in early schools, Prezi describes its software as an educational tool, coining the phrase "virtual whiteboard." Prezi, however, is not only an educational tool. It is also a means of communication.

"A visual story has a flow and narrative, where images and words work together to present an idea or lesson."

As the manifesto goes on, we find Prezi in another frame. It is not just the classroom but the wider context of communication which can be connected to Prezi's functions. As Prezi

\footnotetext{
${ }^{6}$ Z. Kövecses, Metaphor: A Practical Introduction, New York: Oxford University Press, 2002.

${ }^{7}$ Following cognitive linguistic traditions, I am using SMALL CAPITALS to indicate concepts, as opposed to word forms.

${ }^{8}$ C. Fillmore, "Frame Semantics", in Linguistics in the Morning Calm, Linguistic society of Korea (ed.), Seoul: Hanshin, 1982.
} 
tells its viewers a visual story of text and image, which has a flow and a narrative, storytelling and the metaphor COMMUNICATION IS STORYTELLING come into the picture.

"Visual context leads the viewer on a path of discovery."

Prezi, the story-teller tool, has the power to take its audience on a journey. At this point the well-known LIFE IS A JOURNEY (or STORY IS A JOURNEY) metaphor is invoked and added to Prezi's frame.

"Prezi's 3-dimensional canvas is a virtual space where you can delve deeper and pan wider to broaden the conversation."

Prezi's essence is clearly its spatial dimension. Space is thought to contain depth, in terms of communication as well. Making use of the conduIT metaphor, ${ }^{9}$ Prezi's more than 2dimensional space gives more room for thoughts, so that ideas can go through more effectively.

"Prezi's use of spatial metaphor helps your audience remember your content better. Each prezi is a place where you can use spatial metaphor to engage your audience's memory."

As we see, Prezi is admittedly built on spatial metaphors; prezis themselves are viewed as physical spaces which you can fill with your content and use as conduits for your messages. The purpose of (spatial) metaphors is to communicate more effectively, so viewers can make sense of and remember our messages better.

Co-founder Árvai points out that cognitive science plays a key role in how Prezi operates. Spatial relativity is something that enhances our ability to store and recall data, he summarizes.

As we read through the company's manifesto, we can conclude that Prezi has strong metaphorical bases. It invokes metaphors such as COMMUNICATION IS STORYTELLING, LIFE/STORY IS A JOURNEY, VIRTUAL IS PHYSICAL, and COMMUNICATION IS A CONDUIT, on the more general level; and PREZIS ARE CONDUITS, PREZIS ARE CONTAINERS, and PREZIS ARE BOARDS, on the more specific level. As far as Prezi's philosophy is concerned, the company defines its service to be strongly metaphorical. At this point, Hypothesis 1 seems to hold.

\section{Templates Matter}

It is one thing, however, what theory says; reality is another issue. Although we identified a pronounced connection with metaphors in its philosophy, we need to check how Prezi works in practice. We now move on to the examination of its user interface.

Whenever you want to make a prezi presentation, after setting up a profile at www.prezi.com for free, you bump into the following screen (Figure 1).

\footnotetext{
${ }^{9}$ G. Lakoff and M. Johnson, Philosophy in the Flesh: The Embodied Mind and Its Challenge to Western Thought, New York: Basic Books, 1999.
} 


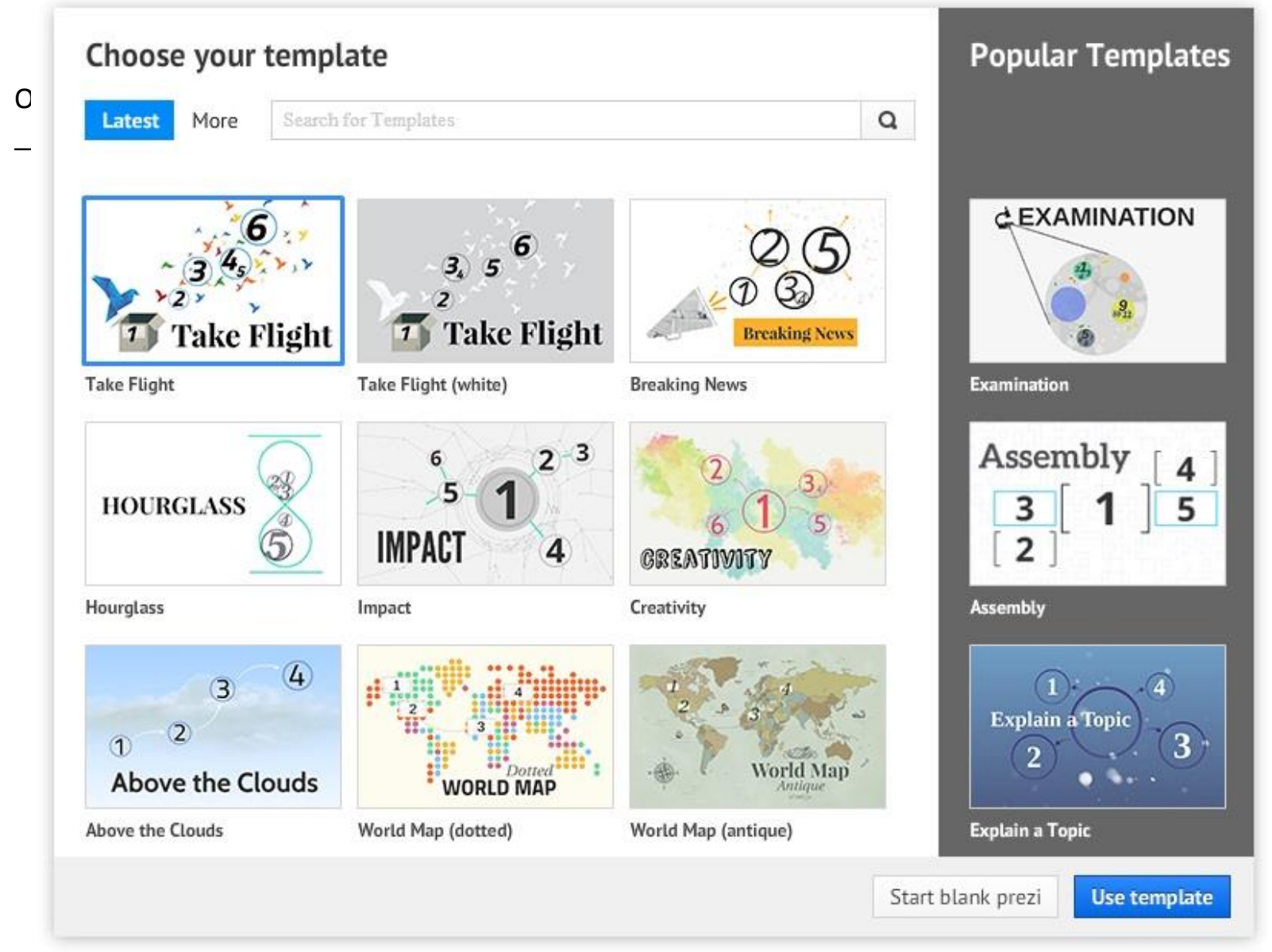

Figure 1: User interface at prezi.com

Before you can reach your infinite presentation canvas and start editing your prezi, you have to "Choose your template". Prezi offers you 92 different, pre-designed templates, with various styles, themes, and contexts. Each of them has a title and a preview, which serve to give you an idea what the given template offers. You have, for example, "World Map", with a given number of stops on different parts of the world. You can also choose "Tactics", which is framed as a football pitch with a couple of players, two goals, and a ball on it. Simpler, more schematic templates are also available, like the tell-tale "Explain a Topic", made up of 4 circles around a central circle, or "Impact", with 6 linked circles, waiting for your content.

If you do not want to, you are not forced to use any of the templates. At the bottom left corner, there is a button saying "Start blank prezi". By pressing it, you will arrive at a completely white canvas to be filled up by your content exclusively.

By considering the structure of the page from a UX (user experience) point of view, we realize how much templates are pushed to the fore, at the expense of the blank canvas. The multitude of the colourful preview pictures of the templates appears much more attractive and conspicuous than the tiny, almost hidden button of the blank. The reason for their central position is that templates are supposed to help and guide the user in how to make an effective prezi presentation. In addition to providing a frame for the content, they control (although not restrict) position, path, rotation, and zooming. Templates support the presentation-making process with design and organization.

Bearing their central role in mind, both on the page and in function, I turned to the analysis of templates as my next step. Out of the 92, I spotted 20 templates that seemed to resonate with well entrenched conceptual metaphors. The analysis revealed, not only do Prezi templates use metaphoric frames, but they belong to the same, structured, metaphor system. 
The Event Structure Metaphor is a generic-level metaphor with image-schematic bases and a universal character. ${ }^{10}$ The central claim behind this system of metaphors is that many aspects of events, like changes, processes, actions, and causes are understood in terms of space, more precisely motion and force. These correlations are believed to be based on bodily experiences, thus, universal. Core metaphors such as CHANGE IS MOTION and CAUSES ARE FORCES manifest themselves in expressions like The image went viral and The image caught everyone's attention.

In the analysis of Prezi templates, the core metaphor proved to be PROCESSES ARE MOTIONS (a verbal example would be He went blind at the age of 14). Around this core metaphor, I could locate 10 other metaphors, from PROGRESS IS FORWARD/UPWARD MOTION through DIFFICULTIES ARE OBSTACLES to GOALS ARE DESTINATIONS. The metaphor system is illustrated in Figure 2.

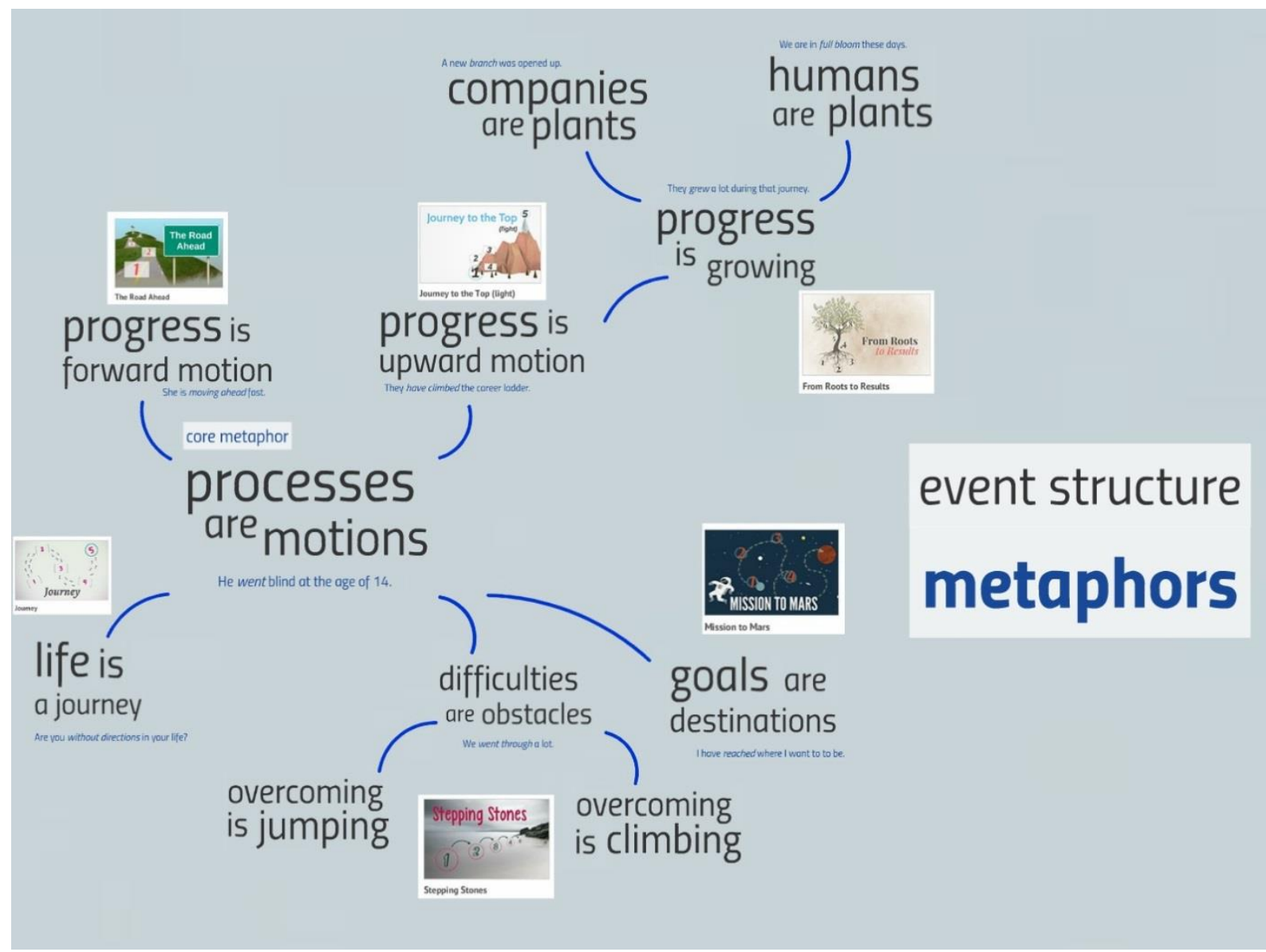

Figure 2: Event Structure metaphors in Prezi templates

Closely related to the core metaphor, we can find templates that use the PROGRESS IS FORWARD MOTION metaphor as their frames. She is moving ahead fast would be a natural verbal manifestation of this conceptual metaphor. As for the template, Prezi offers a number of frames that illustrate a road where progressing with the story means physically going forward (Figure 3/1). PROGRESS IS UPWARD MOTION is another metaphor which is closely correlated. She has climbed the career ladder illustrates the metaphor verbally, while visual

\footnotetext{
${ }^{10}$ G. Lakoff, "The Contemporary Theory of Metaphor", in A. Ortony (ed.), Metaphor and Thought, Cambridge: Cambrige University Press, 1993; N. Yu, The Contemporary Theory of Metaphor: A Perspective from Chinese, Amsterdam \& Philadelphia: John Benjamins, 1998; Z. Kövecses, Metaphor and Emotion: Language, Culture, and Body in Human Feeling, Cambridge: Cambridge University Press, 2003.
} 
examples would be templates displaying a mountain, with the storyline advancing upwards till the conclusion/peak (Figure 3/2).

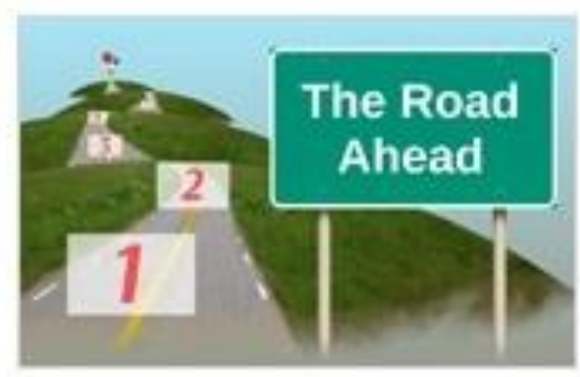

The Road Ahead

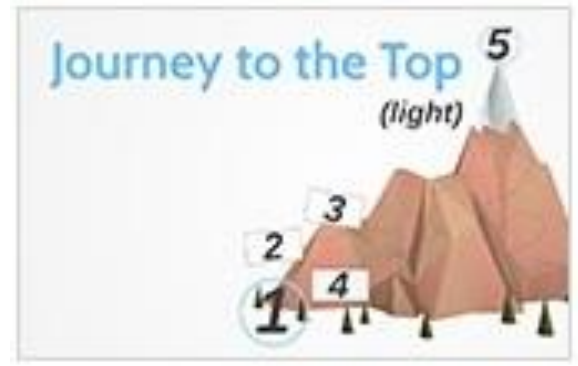

Journey to the Top (tight)

Figure 3: PROGRESS IS FORWARD/UPWARD MOTION in Prezi templates

Progress, seen as upward motion, can be further specified. The metaphor PROGRESS IS GROWING came up a number of times during the analysis. Some of the templates portray plants, most typically trees or flowers, whose key feature is that they develop by growing (Figure 4). The presentation, consequently, progresses by going "from roots to fruits". Some more specific metaphors arising from this are COMPANIES ARE PLANTS and PEOPLE ARE PLANTS ( $A$ new branch opened up and We are in full bloom these days); that is, these templates can be used for storytelling, and more specifically, to describe events of companies and people.

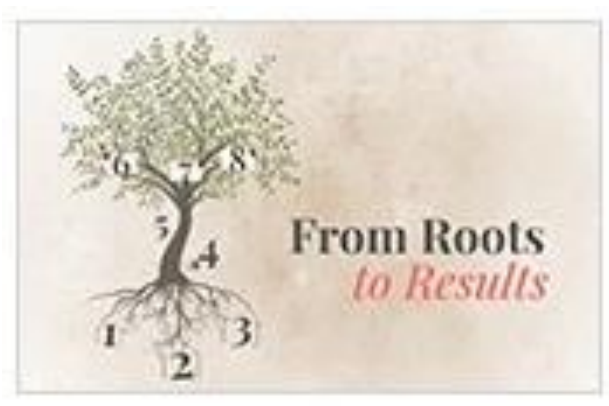

\section{From Roots to Results}

Figure 4: PROGRESS IS GROWING in Prezi templates

The often quoted LIFE IS A JOURNEY pops up just as frequently on Prezi templates as in verbal communication. It is so because we tend to talk about life in terms of journeys. The basis of the LIFE IS A JOURNEY conceptual metaphor is the correlation of bodily experiences between one's journeys and one's life. The experience of being in motion and on a journey, which are inseparable parts of our lives, can be perceived to have a similar structure with the experience of living. The two domains share numerous fundamental correspondences. ${ }^{11}$

\footnotetext{
${ }^{11}$ Z. Kövecses, Metaphor: A Practical Introduction, New York: Oxford University Press, 2002.
} 


$\begin{array}{ll}\text { JOURNEY LIFE } & \\ \text { traveler } & \text { person } \\ \text { co-travelers } & \text { partners } \\ \text { obstacles } & \text { difficulties } \\ \text { crossroads } & \text { choices } \\ \text { destinations } & \text { goals } \\ \text { etc. } & \text { etc. }\end{array}$

To translate this into visual frames, the related templates display some kind of a road or a path, furnished with a certain number of stops (Figure 5/1). Or, when the focus is on the obstacles, the road is made up of stepping stones for example, which the traveler/storyteller needs to overcome one by one (Figure 5/2). If, however, we want to highlight neither the process nor the difficulties of the journey but its goal, then the destination, like Mars, gets the visual-verbal emphasis (Figure 5/3).

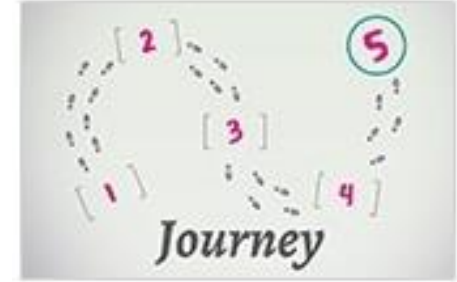

Joumey

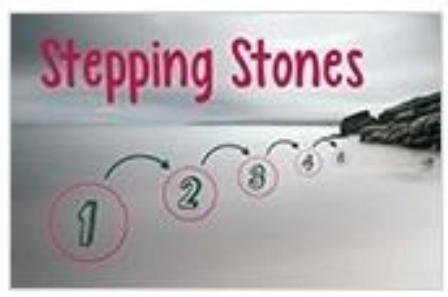

Stepping Stones

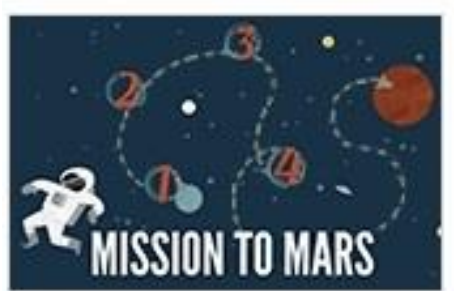

Mission to Mars

Figure 5: LIFE IS A JOURNEY, DIFFICULTIES ARE OBSTACLES, and GOALS ARE DESTINATIONS in Prezi templates

Having identified obvious metaphorical trends in its manifesto, it is now confirmed that Prezi seems to be a metaphorical communication tool even in practice. After the analysis of its user interface, focusing on the templates offered to users when starting a prezi, we have seen that in 20 out of 92 of the templates the framing is metaphorical. Several manifestations of the Event Structure Metaphor System can be tracked on the templates, like PROGRESS IS FORWARD MOTION, PROGRESS IS GROWING Or LIFE IS A JOURNEY. Hypothesis 1, namely that Prezi offers a metaphorical tool, proved right.

\section{Users Matter ${ }^{12}$}

After an investigation into Prezi's website, inspecting how the company sees its software, and into Prezi's user interface, exploring what users are offered to work with, it is time now to screen how users actually use Prezi. We have observed that the software's functioning is based on spatial metaphors, thus, upholding Hypothesis 1. Now we need to examine if and how users make use of this feature, in order to test Hypothesis 2, metaphoricity in Prezi being one reason for Prezi's success or not.

For the analysis of user behaviour, I have adopted materials the company made accessible for me for research reasons. First, I got hold of statistical information on the most popular templates, broken down into regions (Europe, North America, etc.). Secondly, I

\footnotetext{
${ }^{12}$ The research presented in this chapter could not have been done without the kind assistance of Zsuzsa Kovács, Viktor Nagy, and Gábor Vályi, to whom I am grateful.
} 
received the same information about templates I had defined as metaphorical. From these stats, I intended to reveal the popularity and usefulness of (metaphor-based) templates. The third source of information was a database of "random prezis" made with specific templates. In other words, I had access to researching not only how popular a given template seems to be among global users but also how that specific template is translated into prezis. I was specifically interested to see how much metaphors play a role and how frame and content work together.

The analysis brought surprising results. There was one template in the list that overpowered all others. To my astonishment, it was the blank. $30 \%$ of all prezis are made without any template design (the stats hold both globally and regionally). All the other templates had altogether insignificantly low percentages (only $1 . . . \%$ or 0 ....\%). This means that the templates are approximately equally used, with no preference given to metaphorical ones. When I went to discuss my findings with the company's chief UX researcher, she explained to me that it is no surprise I find the data strange. She said these statistics are "noisy" and the company does not even use them. What is to be considered as "accurate result" is that the most popular choice is the blank. Nevertheless, what comes after depends on how Prezi arranges the templates; thus, not on user preference.

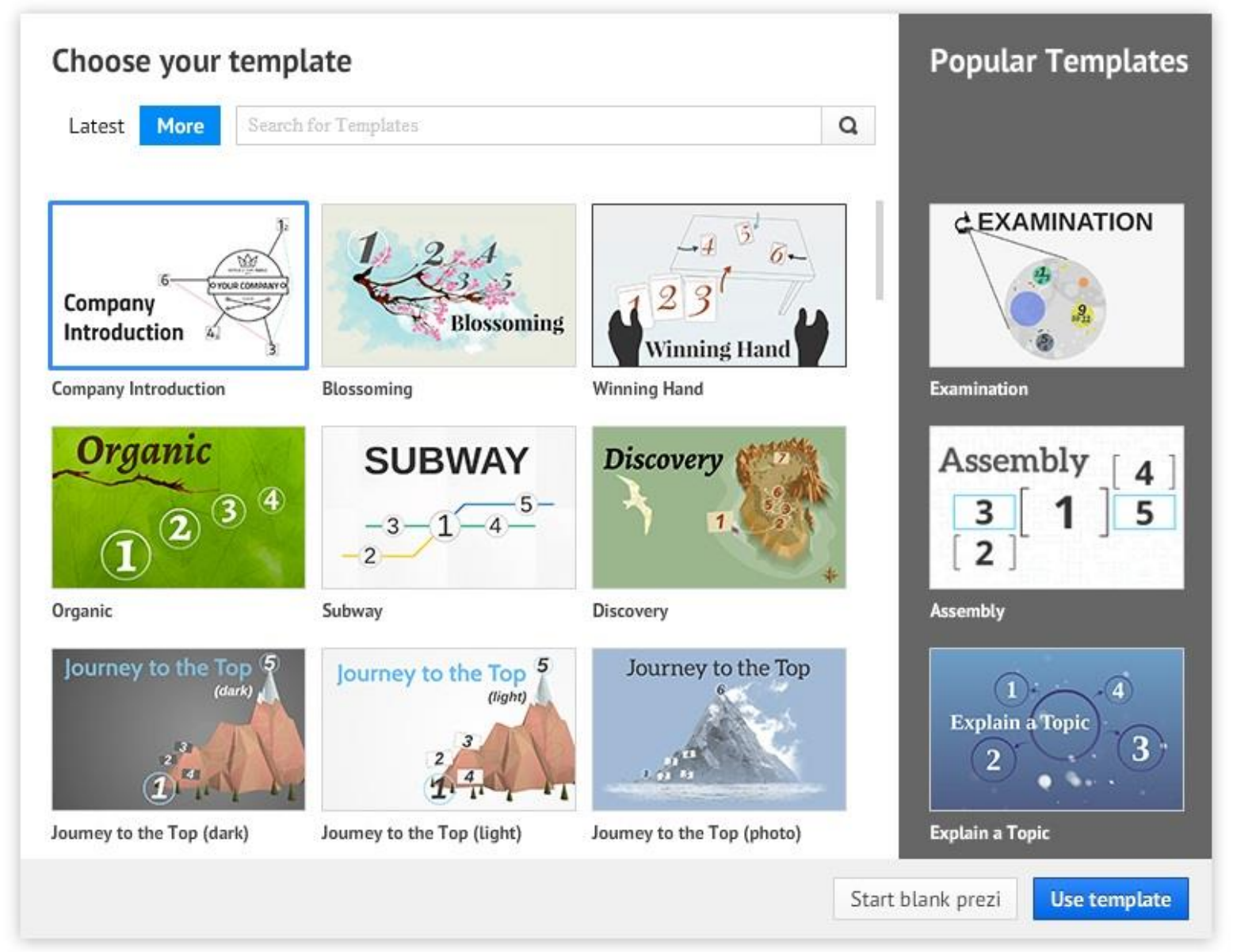

Figure 6: Template arrangement on Prezi's user interface 
We need to go back for a moment to the user interface, so we can observe the arrangement of templates. After a closer look, we realize that templates are divided into 3 sections. On the left, under "Latest", we see 9 templates. On the right, with highlighted background colour, we have 3 templates labeled as "Popular". These are the templates that appear on the first page; consequently, many users encounter only these, and not the 80 other, which are one click away (under the "More" button, as seen on Figure 6).

We would be tempted to think that whatever is categorized under the labels "Latest" and "Popular" are really the latest and the popular (thus, relevant data for our research). It turns out, however, that the reason why these templates are displayed on the front page and pushed for the consideration of users is because they are the ones the company found to be the "most successful". These templates seemed to be the easiest to use, thus, the ones to be recommended for beginners (who will probably not notice or bother to click further).

As a consequence of Prezi's interference with the display of templates, the popularity of a given template can hardly be determined from the available data. The importance of metaphoricity cannot be tested either.

Moving on from the quantitative analysis of statistics, we still have the qualitative examination of template use to test Hypothesis 2. I had access to randomly selected prezis made using a given template. I checked a number of presentations from each of the templates on the "Most popular" list and each of the templates on the "Metaphorical" list to have a fair sample. Firstly, I was examining if and how the template/frame and the content were related. This was interesting mostly in the case of metaphoric templates. Secondly, I also checked if there was any clear use of verbal-visual metaphors in the content.

In the majority of the cases, I found a double no. Most of the prezis did not exhibit a clear connection between the frame the template defined and the content the user added, nor did they use the metaphor offered by the template. Take for example a prezi that made use of the "Blossoming" template. Illustrated around a branch of a blossoming tree, a presentation on diabetes takes shape in front of our eyes. The coupling of the disease and the tree called for a non-literal, metaphorical reading, but the connection did not come selfevidently. Therefore, I checked for verbal anchoring, that is, for some reference in the text to ground the connection. I did not find any. While of course there is no guarantee there is not, but it remained hidden for (at least one of) the viewers. Without a perceived connection, the framing can be disturbing. Nevertheless, since this template was more low-key, calling equally for a mood, as for a specific frame, the dissonance was not too loud.

In cases when the template, of space or football for example, is more detailed and pronounced, the viewer can experience a stronger sense of disharmony, even confusion. To give an example, the SPACE frame (of the template "Mission to Mars") was used to talk about Jennifer Lawrence, an American actress. Not only was there no reference in the text how she is related, when I did a little background study into her filmography and biography, to check if there is any info which is common knowledge, only I was not aware of, still nothing popped up. Similarly, a presentation about 3D printing was placed within the FOOTBALL frame, again with no reference to any kind of connection (Figure 7). 


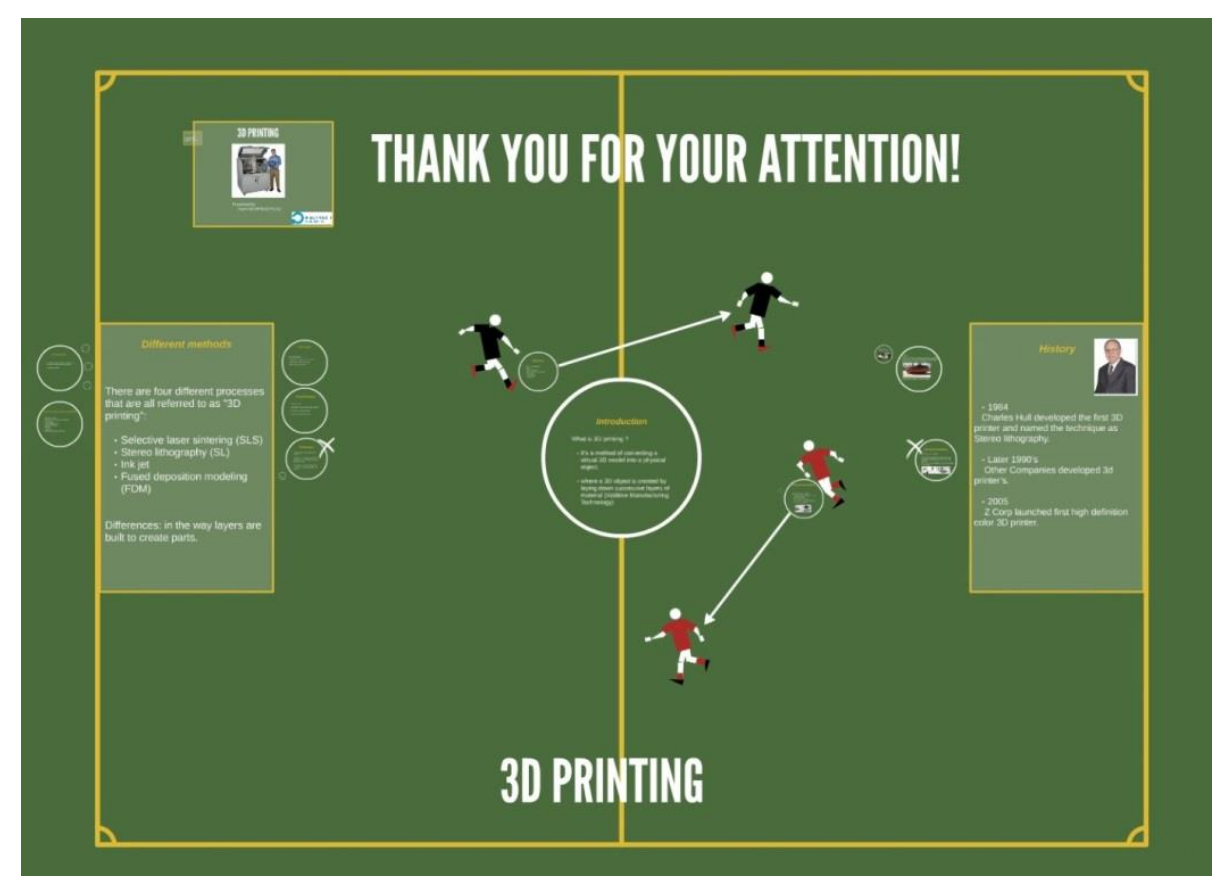

Figure 7: Non-metaphorical template use

In some of the cases, however, I observed a certain degree of consciousness regarding template/frame use. Even though the metaphor invoked by the template is not fully utilized in such prezis, we do identify some traces to connect content and frame, mostly in a metaphoric way. The prezi illustrated in Figure 8 contains a verbal reference to the name and design of the template in its subtitle: a roadmap to in-text citation. Even a one-word anchoring, which places the presentation on citations into a JOURNEY frame with a start and an end, can contribute a lot to meaning-making and understanding, which are primary goals of presentations.

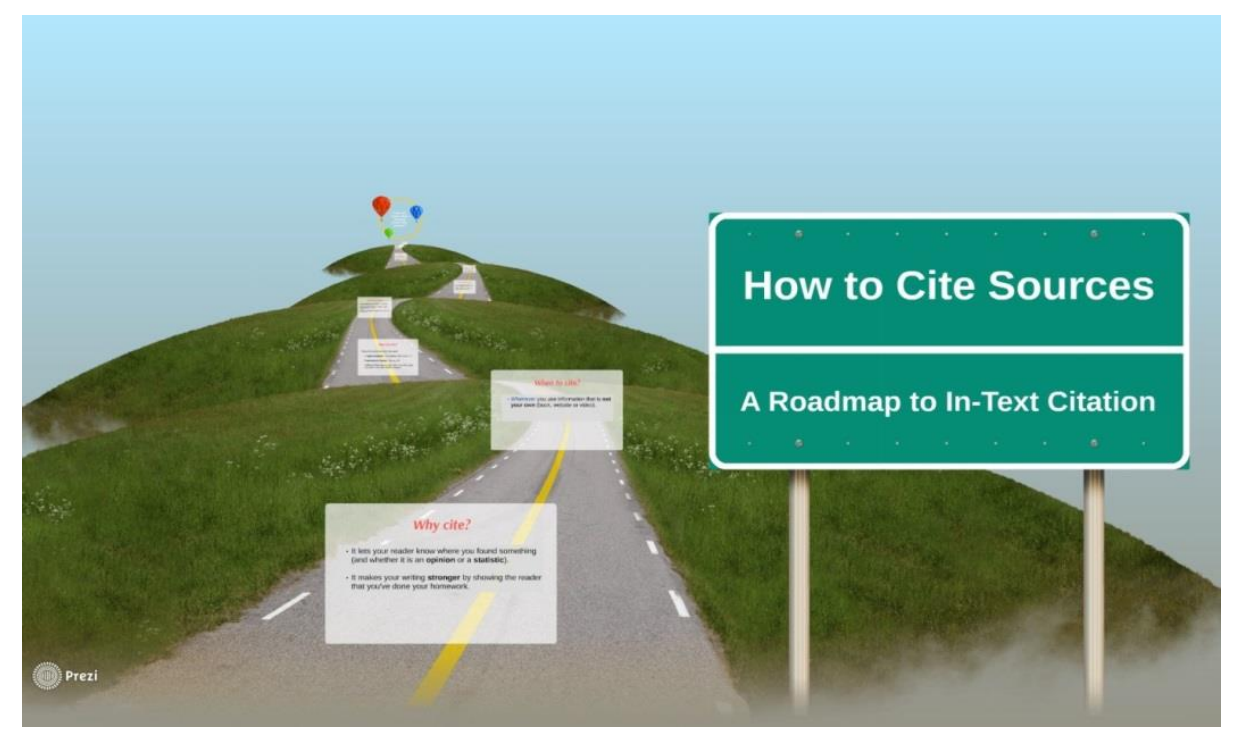

Figure 8: Slightly metaphorical template use 
I found a couple of exceptional prezis, which made compelling use of the metaphoric frames arising from the template. Usually the JOURNEY frame seemed most fruitful. One prezi, for example, illustrated the Afghan folk traditions, from birth to funerals, on a road, invoking the LIFE IS A JOURNEY metaphor. Another portrayed the psychological progress of humans on a path, as if we could walk through life. Presentations that manage to marry verbal and visual, frame and content, often through metaphoric correlation, communicate in a more lucid and more powerful way (see Figure 9 for reference).

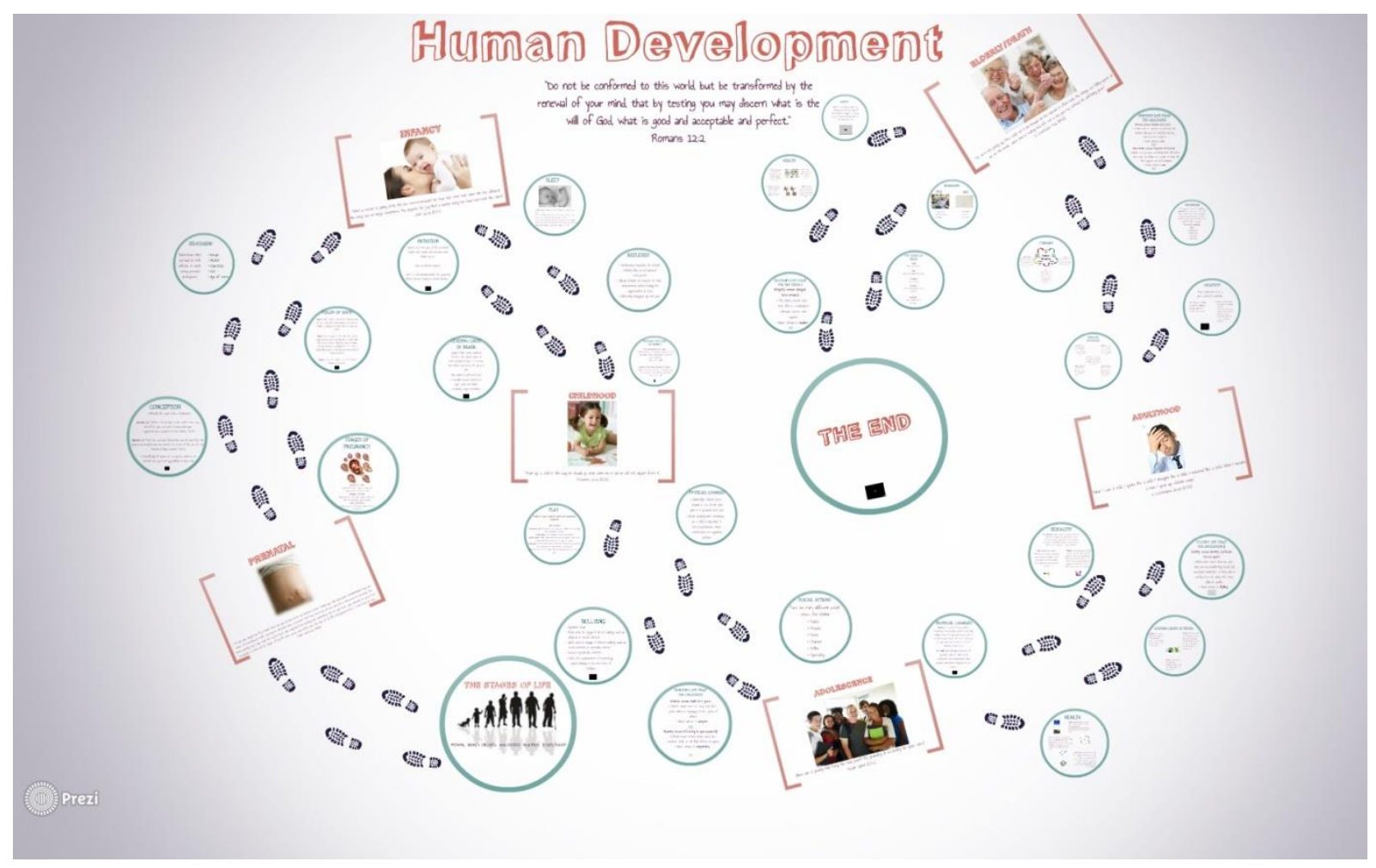

Figure 9: Metaphorical template use

The analysis of random prezis made with specific templates did not prove Hypothesis 2 right. I detected scarce sensitivity for frames and little awareness for metaphors. In the majority of the cases, the template use seems rather arbitrary. It does not appear to "add" to the content, at least not in a straightforward way, nor does the metaphor it entails get elaborated. The hypothesis that proposed that Prezi might be popular because it gives its users a metaphorical tool, which models the way they think, is clearly not defendable. Mainstream users do not seem to like and use Prezi for metaphors.

\section{Conclusions Matter}

Prezi is a presentation software that redefines space and creativity. On an endless canvas we are invited to paint our ideas like they are in our head. Put an image here, place a video over there, draw a line here because they are related, enlarge and tilt the picture, then zoom out to add captions. When we are done putting out everything we had in your head, we set the path we will guide our viewers through. Because PRESENTING IS STORYTELLING and STORYTELLING IS A JOURNEY. The scrutiny of its philosophy and the analysis of its templates revealed, Prezi is 
based on spatial metaphors which pave the way to engaging and memorable communication.

Metaphor is a powerful communicative tool that we use in language, culture, and reasoning. Our thinking is fundamentally metaphoric. ${ }^{13}$ Therefore, Prezi gives a compelling tool in the hands of those who are willing to learn how to manoeuvre with it.

The examination of randomly selected prezis uncovers, however, that only few users take full advantage of this tool. Combining frame and content still proves to be a challenge. The scope of the analysis could not reach to non-template-based prezis or to professional (paying) users, but considering that $70 \%$ of prezis are made with templates and the majority of subscriptions is still for (free) public accounts, the results of this study appear to be representative and the conclusions to be valid.

The dividing line between a half-baked presentation and a well-done prezi is a metaphor, pervasive in our fast-paced world: TIME IS MONEY. How much time can you typically spare from your life to spend on making your presentation slides? If you took the time to do the research, write the paper, sit through the conference, why not give your presentation the time it needs?

Your ideas matter.

https://prezi.com/4wqsoypgi8bj/metaphors-matter-a-visual-presentation/

\footnotetext{
${ }^{13}$ G. Lakoff and M. Johnson, Philosophy in the Flesh: The Embodied Mind and Its Challenge to Western Thought, New York: Basic Books, 1999.
} 